\section{Analysis of the causes of the seizure and destruction of carcasses and organs in a slaughterhouse in central Italy in the 2010-2016 period}

\author{
Margherita Ceccarelli, ${ }^{1}$ Elisa Leprini, ${ }^{1}$
}

Paola Sechi, ${ }^{1}$ Maria Francesca Iulietto, Luca Grispoldi, ${ }^{1}$ Enzo Goretti, ${ }^{2}$

Beniamino Terzo Cenci-Goga ${ }^{1}$

${ }^{1}$ Department of Veterinary Medicine, University of Perugia; ${ }^{2}$ Department of Chemistry, Biology and Biotechnology, University di Perugia, Italy

\begin{abstract}
Meat safety and hygiene are fundamental issues for producers and endusers. To achieve these goals, the inspection of carcasses and organs at slaughter is critical. The results of post-mortem inspection are the basis for planning preventive measures against consumer risks and for limiting economic losses. In this retrospective study, the causes of the seizure and destruction of carcasses and organs were analysed at a slaughterhouse in central Italy from 2010 to 2016. 436,646 slaughtered animals were taken into consideration, for a total of 61,799 seizures $(73.29 \%$ pigs, $23.87 \%$ cattle, $2.77 \%$ sheep and $0.07 \%$ horses). The organs or groups of organs that most frequently showed lesions in pigs were liver $(72.38 \%)$, heart $(10.77 \%)$ and pluck $(10.20 \%)$; in cattle, lungs $(64.86 \%)$, liver $(31.20 \%)$ and stomachs (11.63\%); in sheep, liver $(77.15 \%)$, pluck $(18.70 \%)$ and lung $(3.80 \%)$; in horses, liver $(75.56 \%)$, kidney $(68.89 \%)$ and lung $(31.11 \%)$. Among the diagnoses, parasitic diseases of the liver (ascariasis and distomatosis) were especially frequent in all species, followed by pericarditis and polyserositis in pigs and diseases affecting the respiratory system in cattle. The data obtained show that postmortem inspection is of fundamental importance for limiting risks for the consumer and ensuring meat safety. It is also evident, even more than ten years after the coming into force of the so-called hygiene package regulations, that the slaughterhouse can still act as an epidemiological observatory to provide the data needed for the development of plans for the control and eradication of the most frequent diseases in the area.
\end{abstract}

\section{Introduction}

The safety of food of animal origin is guaranteed in our country by the synergy between the control authorities and the food industry operators in accordance with that established by the so-called hygiene package constituted by Regulations (EC) 852/2004, $853 / 2004,854 / 2004$ and $882 / 2004$, applied to all foodstuffs from primary production to distribution.

The hygiene package aims to ensure a high level of protection of human health for the European community citizens by ensuring the placing on the market of healthy and safe food. One of the key goals of the hygiene package was also to harmonize the legislation of all member countries in order to define the same food safety requirements. Through the hygiene package, in fact, all the states members have the same criteria regards the hygiene of the food production and therefore the sanitary checks are carried out according to the same standards throughout the territory of the European Community.

Regulation 852/2004 establishes general rules in matter of hygiene of any alimentary product and is therefore addressed to all the food industry operators, regardless of the food which they produce or their role in the food chain. The legislation makes compulsory the adoption of the HACCP system, which is a self-control method that aims to Identify and analyse the possible risks during the production of a food, to define the necessary means to neutralize them and to ensure that these means are implemented efficiently.

Regulation 853/2004 establishes specific hygiene standards that integrate those contained in Reg. 852/2004 and are referred only to those who produce food of animal origin.

Regulation 854/2004 lays down specific rules on the organization of official controls on products of animal origin and is directed to the competent authority which carries them out.

Regulation 882/2004, on the other hand, lays down general rules to carry out official controls on all foods which are produced or marketed on the territory of the EC (not only those of animal origin).

Recently added to this was Regulation (EU) $625 / 2017$ of 15 March 2017, which came into force in April 2017 and will be applied starting on 14 December 2019. This is a very lengthy regulation, consisting of 167 Articles and 5 Annexes, that will amend Regulations (EC) 854/2004 and 882/2004 concerning official controls, as well as amending and repealing many other regulations and directives.
Correspondence: Luca Grispoldi, Department of Veterinary Medicine, University of Perugia, Piazza dell'Università 1, 06100 Perugia (PG), Italy.

Tel.: +39.342.8391290 - Fax +39.075.585.7976. E-mail: grisluca@outlook.it

Key words: Slaughterhouse, Inspection, Seizure of carcasses.

Contributions: the authors contributed equally. Conflict of interest: the authors declare no potential conflict of interest.

Received for publication: 4 September 2017. Revision received: 30 October 2017.

Accepted for publication: 31 October 2017.

This work is licensed under a Creative Commons Attribution-NonCommercial 4.0 International License (CC BY-NC 4.0).

CCopyright M. Ceccarelli et al., 2018 Licensee PAGEPress, Italy

Italian Journal of Food Safety 2018; 7:6899

doi:10.4081/ijfs.2018.6899

In the meat sector, the ASL (local health board) veterinarian, defined as the Official Veterinarian by current laws, is responsible for supervision and inspections in slaughterhouses.

Among the tasks of the Official Veterinarian is post-mortem inspection, which is essential for identifying alterations to the carcass or organs that could constitute a serious danger to the health of the consumer.

The analysis of the causes of partial and total seizures ordered during inspection is a valid tool for studying the type and prevalence of lesions found in slaughtered animals, as well as for investigating the trend of the major diseases over time. This makes it possible to understand which main public health hazards are transmitted by meat, and thus to take corrective actions to reduce the prevalence of these risks and to ensure the safety of the finished product. The scheduled actions that can be established to lower the presence of these diseases have a twofold purpose. On the one hand, they provide protection for the health of the consumer and, on the other hand, they defend the economic interests of the farmer, as the finding of these alterations brings about their exclusion from consumption. The slaughterhouse is a crucial point for focusing on controls, but the safety of foods of animal origin must be pursued at every stage of the supply chain. The achievement of high production standards requires the active participation of all the operators in the food 
industry working at every stage of production. Only adequate education and training and a strong sense of responsibility in each food industry operator can help to achieve this goal. The veterinarian must be an attentive supervisor of the tasks carried out by the food industry operators as well as the ultimate guarantor for the safety of the food that ends up on people's tables every day.

\section{Materials and Methods}

This study was conducted at a slaughterhouse in central Italy. The slaughterhouse is recognized pursuant to Regulation (EC) $853 / 2004$. The slaughter databases were examined for the 2010-2016 period in order to record the number of partial seizures of organs and total seizures of carcasses of domestic ungulates (cattle, sheep/goats, pigs) and domestic solipeds (horses) regularly slaughtered at this facility.

The results of the post-mortem inspection of each slaughtered animal were recorded by the Official Veterinarian in special computerized registers, in which each disease is checked with a special mark and each individual animal is indicated with its respective slaughter number.

The recording was done using an Asus X55A Series laptop computer with an Intel Pentium B970 processor and Windows 7 Professional 2009 operating system. The subsequent transfer of the data was done with Microsoft Excel software for Windows 7. The Excel spread sheet, saved in the format of an electronic .xls spread sheet, was imported into FileMaker Pro 10 databases for subsequent statistical processing.

The characteristics investigated are the frequency of total and partial seizures, the type and frequency of lesions found at the post-mortem health examination divided by the animal species concerned and, lastly, their trend during the period analysed.

\section{Results}

A total of 437078 livestock animals were slaughtered over the time period analysed, divided as follows: 58,483 cattle (13.38\%), 332,504 pigs $(76.07 \%), 46,019$ sheep/goats $(10.53 \%)$ and 72 horses $(0.02 \%)$.

The total number of total and partial seizures during the seven years analysed came to 61,799 , representing $14.13 \%$ of the animals slaughtered. More specifically, there were 14,595 partial seizures for cattle, 44,693 for pigs and 1666 for sheep/goats. The number of carcasses seized and destroyed totalled 149 for cattle, 576 for pigs, 45 for small ruminants and 0 for horses (Table 1).

In horses, all the kidneys and livers were excluded from human consumption because of the prophylaxis for cadmium as required by current laws.

It can be noticed that in general partial seizures are more frequent than the destruction of the entire carcass. More specifically, for cattle, $99 \%$ of all seizures are for organs, whereas the carcass is sent to be destroyed in $1 \%$ of the cases. For pigs, the situation is more or less the same, as partial seizures account for $98.8 \%$ of the total number, while only $1.2 \%$ is total seizures. A similar scenario is also found with sheep and goats, as only $2.63 \%$ of the carcasses were destroyed, compared to $97.36 \%$ of partial seizures.

The analysis of the data shows that the organ most often seized in cattle is undoubtedly the lung, with a total of 9563 seizures $(64.86 \%)$, followed by the liver with 4600 seizures $(31.2 \%)$ and the stomachs with 1715 seizures $11.63 \%$ ). Lesser numbers were found regarding pluck, seized 948 times, damaged kidney 648 times, and the heart, involved in 547 cases (Table 2).

The most common causes for partial seizure of the lung were the inflammatory diseases of the pleura and parenchyma, thus pleurisy, pneumonia and bronchopneumonia.
Pleurisy was diagnosed 4897 times $(51.20 \%)$, and as regards instead the lung parenchyma, there were 1888 cases of pneumonia (19.74\%) and 1398 of bronchopneumonia (14.62\%).

As for the liver, the main causes of seizure were liver distomatosis, which occurred in $1090(23.7 \%)$ cases, and liver abscesses reported 1067 times $(23.2 \%)$ at inspection. Inflammatory processes affecting the serous membrane of the organ (perihepatitis) were found 468 times during the entire period, together with 497 cases of liver adherence; the latter could be interpreted as the result of previous phlogosis. Also worthy of note is hepatic hydatidosis, diagnosed 309 times, which, although accounting for only $6.8 \%$ of the cases of liver disease, cannot be disregarded because of its zoonotic importance.

Stomachs are the third most discarded organ in cattle at inspection. Adherences were diagnosed in 715 cases $(41.69 \%)$, and foreign body lesions in 706 cases $(41.17 \%)$.

The three most important causes of the seizure and destruction of the entire carcass in the cattle were septicaemia $(20.81 \%)$, peritonitis $(20.13 \%)$ and cachexia $(12.08 \%)$.

In pigs, the liver is definitely the most seized organ, such that out of a total of 44693 partial seizures, it was eliminated in 32764 cases, and therefore the liver alone accounted for $72.38 \%$ of all partial seizures

Table 1. Total number of total and partial seizures during the 2010-2016 period.

\begin{tabular}{lcc} 
Animal species & No. partial seizures & No. total seivalues \\
Pigs & 44693 & 576 \\
Cattle & 14595 & 149 \\
\hline Sheep & 166 & 45 \\
Horses & 81 & 0 \\
\hline
\end{tabular}

Table 2. Seized organs in cattle during the 2010-2016 period.

\begin{tabular}{lcc} 
Organ & No. seized organs & Percentage* \\
Lung & 9563 & 64.86 \\
Liver & 4600 & 31.20 \\
\hline Stomachs & 1715 & 11.63 \\
Plunk & 948 & 6.42 \\
\hline Kidney & 648 & 4.39 \\
Heart & 547 & 3.70 \\
\hline Muscle & 163 & 1.10 \\
Head & 99 & 0.67 \\
\hline Limb & 52 & 0.35 \\
Tongue & 25 & 0.16 \\
\hline Spleen & 2 & 0.01
\end{tabular}

*Percentage calculated on total partial seizures for cattle. 
(Table 3). The disease that indisputably dominates in the liver is ascariasis, found in 31541 cases, and therefore it alone explains $96.2 \%$ of the liver seizures. All other lesions in this organ are of negligible importance in terms of prevalence.

The second most eliminated organ in the pig is the heart $(10.77 \%)$, due to pericarditis in $99.8 \%$ of cases of seizure of the cardiovascular system. Pig pluck represents $10.20 \%$ of the partial seizures, and polyserositis was found in 4467 cases out of a total of 4618 plucks eliminated. It can easily be inferred that polyserositis is a remarkable disease that by itself contributes enormously to the seizure of lungs, heart and liver together. The musculoskeletal apparatus in pigs should also be mentioned, given that it was subjected to seizure 1898 times, with 1401 cases caused by the presence of muscle abscesses.

Among the causes of seizure and destruction of the entire pig carcass, widespread abscesses are the first cause for exclusion from consumption, having been found 208 times out of a total of 547 seized carcasses, thus accounting for $36 \%$ of the reasons for unfitness. In second place we find peritonitis, found in 155 pigs $(28.34 \%)$, while septicaemia and cachexia respectively caused the removal from the market of 60 (10.97\%) and $46(8.41 \%)$ animals.

In sheep/goats, the organ most affected was the liver, with 1320 cases, representing $77.15 \%$ of all partial seizures, followed by pluck (18.70\%) and lung (3.8\%) (Table 4). Among the diseases, a clear predominance of parasites causing hepatitis was observed 1271 times, thus in $96.2 \%$ of all liver lesions. The pluck was also discarded in $79.69 \%$ of cases due to the presence of parasitic lesions.

As for total seizures, peritonitis is predominant, with 16 out of $45(35.56 \%)$ carcasses, followed by jaundice, which made destruction necessary 9 times $(20 \%)$, while the remaining causes of exclusion are equally divided among those provided for in slaughter records.

The percentage of partial and total seizures calculated in relation to the total number of animals slaughtered annually is highest in bovines, reaching an average of $25 \%$ with a peak of $31.02 \%$ in 2015 . Next come pigs, in which the percentage of seizures remained fairly constant over the period under consideration, with values ranging from $10.79 \%$ in 2010 to $16.22 \%$ in 2014. Lastly, in sheep/goats a decreasing trend in seizures was observed, dropping from $9.04 \%$ in 2011 down to $1.47 \%$ in 2016 (Figure 1).

\section{Discussion}

An observation worthy of attention regards the trend of the main diseases over time (Figure 2). During the entire period investigated, it can be seen that the diseases most frequent in pigs were diagnosed rather consistently over the years. In particular, ascariasis was found in percentages that varied little over time, going from a $97.18 \%$ in 2010 , but at other times it repeatedly reached values around 96\%. that the general trend obtained from the data shows a presence of liver lesions attributable to Ascaris suum constant throughout the period. In pigs, similar considerations may also be made for pericarditis and polyserositis.

In cattle, the study of the development of diseases such as pleurisy, the most frequent cause of partial seizures in this species, suggests a decline in the number of cases during the first six years of the research, dropping from $66.27 \%$ in 2010 to $49.64 \%$ in 2015 , and then rising again up to $52.03 \%$ in 2016. Likewise, liver distomatosis also decreased over time. In 2010, there was a minimum of $94.08 \%$ in 2012 and reaching Therefore, it can reasonably be concluded

peak of $30.12 \%$ of these liver parasites, which then dropped down to $16.90 \%$ in 2015 , the year in which it was diagnosed least frequently.

Due to its zoonotic importance, hepatic hydatidosis cannot be ignored. Echinococcus granulosus in the cattle liver was found to vary annually from year to the next year. In fact, there was a very sharp increase from 2010 to 2011 , going from $2.78 \%$ to $8.57 \%$, then falling back to $5.14 \%$ in 2012 ; in the years 2013-2014 it always remained above $8 \%(8.83 \%$ and $8.14 \%$, respectively), and in the last year of the study, 37 cases of hepatic hydatidosis were recorded, corresponding to $6.14 \%$. In sheep/goats, parasitic hepatitis went from the absolute greatest frequency found in $2010(99.74 \%)$ to a decidedly lower frequency $(81.25 \%)$ in 2016 , still remaining a major cause of the seizure and destruction of livers in small ruminants.

In the context of the hygiene package, the active involvement of all food chain operators is considered essential to achieve the highest levels of consumer protection and the exchange of information within the several phases of the field-to-table chain are an important tool to achieve the desired security targets.

Table 3. Seized organs in pigs during the 2010-2016 period.

\begin{tabular}{lcc} 
Organ & No. seived organs & Percentage* \\
Liver & 32,764 & 72.38 \\
Heart & 4877 & 10.77 \\
\hline Pluck & 4618 & 10.20 \\
Muscle & 1898 & 4.19 \\
\hline Limb & 356 & 0.78 \\
Lung & 57 & 0.12 \\
\hline Head & 45 & 0.09 \\
Kidney & 31 & 0.06 \\
\hline Udder & 9 & 0.01 \\
Spleen & 2 & 0.004 \\
Tongue & 1 & 0.002
\end{tabular}

*Percentage calculated on total partial seizures for pigs.

Table 4. Seized organs in sheep during the 2010-2016 period.

\begin{tabular}{lcc} 
Organ & No. seized organs & Percentage* \\
Liver & 1320 & 77.15 \\
Pluck & 320 & 18.70 \\
\hline Lung & 65 & 3.80 \\
Muscle & 7 & 0.40 \\
\hline Head & 6 & 0.35 \\
Limb & 4 & 0.23 \\
Kidney & 1 & 0.05 \\
Heart & 1 & 0.05 \\
\hline Intestine & 1 & 0.05
\end{tabular}

*Percentage calculated on total partial seizures for sheep. 


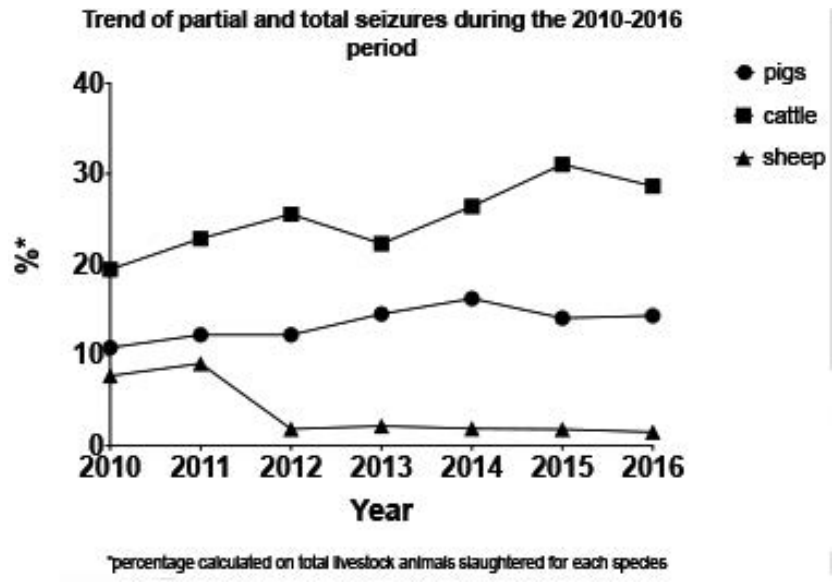

Figure 1. Trend of partial and total seizures during the 20102016 period.

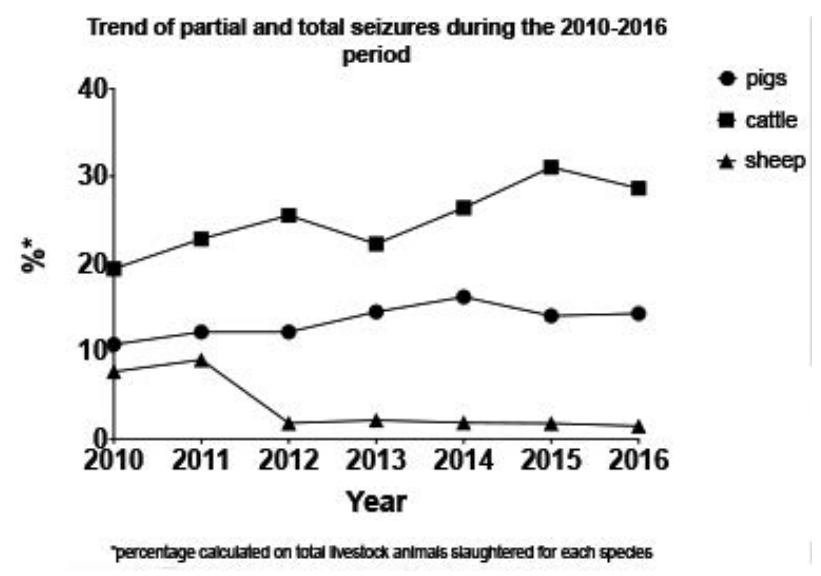

Figure 2. Trend of major diseases in the 2010-2016 period.
For each animal sent to the slaughterhouse, the farmer must therefore provide to the slaughterhouses' responsible information about the food chain (ICA) that will enable a prior assessment of the relevant risks and the taking of responsible decisions before to admit animals to the slaughter.

Is also expected a return of information to the farmer owner of the slaughtered animals which is responsibility of the official veterinarian who must inform the farmer of the results of the checks carried out on slaughtered animals where they are indicative of the presence of diseases which could have an impact on public and animal health or situations that compromise animal welfare.

The trend of the main diseases observed in this study, which remained stationary during the analysed period, seems to suggest that there is a communication failure between controlling authorities and farmers (as producers of animals). It is desirable to improve the exchange of information in order to reduce the prevalence of certain diseases in the territory.

\section{Conclusions}

The data collected showed a sharp prevalence of diseases of parasitic aetiology in virtually all slaughtered species. More specifically, parasitic hepatitis is dominant in pigs, whereas for cattle, in addition to the liver distomatosis, the diseases most frequently found were lung inflammations, but the aetiology in this case is not always attributable to parasites. For sheep/goats, parasites were the main source of lesions that damage the entire pluck. This provides evidence of the presence of these biological agents within the farms and makes them very much present-day illnesses, and anything but diseases of the past.

The veterinarian's role in meat inspection is therefore absolutely necessary for the diagnosis of diseases that are potentially dangerous for the consumer. In order to make the diagnosis more accurate, it would also be advisable to back up the inspections with collateral diagnostic methods.

The data obtained show that postmortem inspection is of fundamental importance for limiting risks for the consumer and ensuring meat safety. It is also evident, even more than ten years after the coming into force of the so-called hygiene package regulations, that the slaughterhouse can still act as an epidemiological observatory to provide the data needed for the development of plans for the control and eradication of the most frequent diseases in the area.

\section{References}

Berends BR, Snijders JMA, Van Logtestijn JG, 1993. Efficacy of current EC meat inspection procedures and some proposed revisions with respect to microbiological safety: a critical review. Vet Rec 133:411-5.

Borrello S, Guizzardi S, 2013. Verso una moderna ispezione delle carni al macello. 30 giorni. 15-18.

Bozzo G, Ceci E, Pinto P, 2009. Determinazione residui di cadmio nel muscolo, nel fegato e nel rene di equini macellati nella Provincia di Bari. AIVI 5:40-3.

Bueno LS, Caldara FR, Naas IA, Salgado DD, Garcìa RG, Almeida Paz ICL, 2013. Swine Carcass Condemnation in
Commercial Slaughterhouses. Revista MVZ Cordoba 18:3836-42.

Cenci Goga BT, 2005. Recenti attività dei gruppi di lavoro di esperti dell'EFSA sulla revisione dei metodi di ispezione delle carni. Progresso Veterinario 6:2457.

Cenci Goga BT, 2010. L'infezione da Echinococcus granulosus nel cane: la prevenzione dell'echinococcosi cistica nell'uomo potrebbe ricominciare da qui. Praxis Veterinaria 31:7-13.

Cenci Goga BT., Budelli L, Branciari R, Ranucci D, Miraglia D, Dell'Erba M, 2007. Considerazioni sulla semplificazione dei metodi di ispezione post mortem in rapporto ai sequestri e distruzioni effettuati in un macello dell'Italia centrale nel periodo 20002004. Atti LXI Convegno SISVet, Salsomaggiore Terme, 347-348.

Cenci Goga BT, Fermani AG, 2014. Sanità pubblica veterinaria e igiene degli alimenti, Point Veterinaire Italie, Milano.

Cenci Goga BT, Miraglia D, Ranucci D, Branciari R, Budelli L, McCrindle CM, Cioffi A, Mammoli R, 2007. An in vitro system for the comparison of excision and wet-dry swabbing for microbiological sampling of beef carcasses. J Food Prot 70:930-6.

EFSA, 2004. Opinion of the European Food Safety Authority on BSE risk from dissemination of brain particles in blood and carcass following stunning. EFSA Journal 123;1-4.

EFSA, 2004. Opinion of the Scientific Panel on Biological Hazard on Revision of Meat Inspection for Beef raised in Integrated Production Systems. EFSA Journal 141:1-49.

EFSA, 2004. Opinion of the Scientific Panel on Biological Hazards on the request 
from the Commission on Meat Inspection Procedures for Lambs and Goat. EFSA Journal 54:1-48.

EFSA, 2004. Opinion of the Scientific Panel on Biological Hazards on the suitability and details of freezing methods to allow human consumption of meat infected with Trichinella or Cysticercus. EFSA Journal 141:1-56.

EFSA, 2011. Overview on current practices of meat inspection in the EU. EFSA Journal 8:1-152.

EFSA, 2011. Technical specifications on harmonised epidemiological indicators for public health hazards to be covered by meat inspection of swine. EFSA Journal 9:1-125.

Ezatpour B, Hasanvand A, Azami M, Mahmoudvand H, Anbari K, 2014. A slaughterhouse study on prevalence of some helminths of cattle in Lorestan provience, west Iran. Asian Pac J Trop Dis 4:416-20.

Garofalo D, Budelli L, Cambiotti V, Cenci Goga BT. Considerazioni sull'ispezione post-mortem in rapporto ai sequestri e distruzioni effettuati in un macello dell'Italia centrale nel periodo 2004 2009. Ital J Food Safety 1:21-3.

Gastaldo A, Rossi A, Bortolazzo E, Borciani M, Bertolini A, Gorlani E, 2013. Il benessere degli animali e la qualità delle carni. Suinicoltura 11:28-31.

Gezu M, Addis M, 2014. Causes of Liver and Lung Condemnation among Apparently Healthy Slaughtered Sheep and Goats at Luna Abbattoir, Modjo, Ethiopia. Adv Biol Res 8:251-6.

Griglio B, Sattanino G, Siviero T, Guarda F, 2004. Valutazione sulle patologie rilevate nei suini macellati in Piemonte. Large Anim Rev 10:35-44.

Hajimohammadi B, Oryan A, Zohourtabar A, Ardian M, Shokuhifar M, 2014. Rate of carcass and offal condemnation in animals slaughtered at Yazd Slaughterhouse, central Iran. Asian Pac J Trop Biomed 4:736-9.

Jahed Khaniki GR, Kia EB, Raei M, 2012. Liver condemnation and economic losses due to parasitic infections in slaughtered animals in Iran. J Parasit Dis 37:240-4.

Jithendran KP, Bhat TK, 1996. Prevalence of dicrocoeliosis in sheep and goats in Himachal Pradesh, India. Vet Parasitol 61:265-71.

Knecht D, Jankowska A, Zalesny G, 2012. The impact of gastrointestinal parasites infection on slaughter efficiency in pigs. Vet Parasitol 184:291-7.

Lawrie RA, 2012. Scienza della carne, Edagricole, Milano.

Marcato PS, 1995. Patologia animale e ispezione sanitaria delle carni fresche. Edagricole- Edizioni Agricole, Bologna.

Marcato PS, 2008. Patologia sistematica veterinaria, Edagricole, Milano.

Mateus TL, Cruzeiro ALF, Rocha H, VieiraPinto MM, 2015. Economic impact of hepatic rejections caused by Ascaris suum in swine during post mortem inspection at slaughterhouse. Safepork 2015 Posters, 269-272.

Mokhber Dezfouli MR, Abbasi J, Sadeghian Chaleshtori S, Akbarein H, Khanjari A, 2016. Prevalence of Liver Parasitic Infections in Sheep and Cattle Slaughtered in Torbat-E-Heidarieh Abbattoir, Northeast Iran. Iran J Rum Health Res 1:17-22.

Nielsen SS, Nielsen GB, Denwood MJ, Haugegaard J, Houe H, 2015. Comparison of recording of pericarditis and lung disorders at routine meat inspection with findings at systematic health monitoring in Danish finisher pigs. Acta Vet Scandin 57:1-8.
Paladino E, Bonetti S, Conti G, Gandolfi C, 2011. Adeguamento strutturale dei macelli a capacità limitata ai fini del riconoscimento ai sensi del Regolamento 853/2004. Esperienze della A.S.L. della Provincia di Bergamo. A.I.V.I. online, 1, 171-175.

European Commission, 2001. Regulation n. 466/2001, 8/3/2001.

European Commission, 2004. Regulation n. 852/2004, 29/4/2004.

European Commission, 2004. Regulation n. 853/2004, 29/4/2004.

European Commission, 2004. Regulation n. 854/2004, 29/4/2004.

European Commission, 2004. Regulation n. 882/2004, 29/4/2004.

European Commission, 2005. Regulation $n$. 2075/2005, 5/12/2005.

European Commission, 2006. Regulation n. $1881 / 2006,19 / 12 / 2006$.

European Commission, 2008. Regulation n. 629/2008, 2/7/2008

European Commission, 2004. Regulation $n$. 219/2014, 7/3/2014

European Commission, 2017. Regulation n. 625/2017, 15/3/2017.

FAO/WHO Expert Meeting, 2012. Multicriteriabased ranking for risk management of food-borne parasites. Roma.

Salvi S, Caroli A, Bolla P, Cancelli P, Monti A, Tamborrino P, 2000. Il monitoraggio delle patologie presso il pubblico macello di Milano. Atti della Società Italiana di Buiatria, XXXII, 241-249.

Taylor MA, Coop RL, Wall RL, 2010. Parassitologia e malattie parassitarie degli animali domestici. Emsi.

Valieva Z, Sarsembaeva N, Valdovska A, Ussenbayev AE, 2013. Impact of Echinococcosis on Quality of Sheep Meat in the South Eastern Kazakhstan. Asian Australas J Anim Sci 27:391-7. 